\title{
The use of the term 'limnology' and its scientometrics consequences for limnologists
}

\author{
Diego Fontaneto, ${ }^{*}$ Alejandro Martínez, ${ }^{1}$ Stefano Mammola,,${ }^{1,2}$ Aldo Marchetto ${ }^{1}$ \\ ${ }^{1}$ National Research Council, Water Research Institute, Largo Tonolli 50, 28922 Verbania Pallanza, Italy; ${ }^{2}$ Finnish Museum of Natural \\ History (LUOMUS), University of Helsinki, Helsinki, Finland
}

\begin{abstract}
Jargon is the specialised vocabulary of any science: it allows the creation of new terms to define concepts and it removes ambiguity from scientific communication. Yet, it may also hinder understanding for a broader audience. Given that the Journal of Limnology has jargon in its title, we here investigate the impact of the term 'limnology' on the way limnologists work, publish their research, and attract the interest of other scientists. We do so by comparing scientometric features of papers published from 1965 to 2020 that used the term 'limnology' against papers on similar topics but that used the term 'lake ecology' or 'hydrobiology', and to the marine counterpart of papers that used the term 'oceanography'. We found that papers using the term limnology score worse than those of the other topics in terms of both publication output and scientific impact. Limnologists may need to use other terms in addition to 'limnology' to reach a broader scientific audience.
\end{abstract}

\section{INTRODUCTION}

The long-lasting discussion about the good and bad of scientific jargon remains open (Montgomery, 1989; Nation, 2006; Bullock et al., 2019; Martínez and Mammola, 2021). On the one hand, to achieve clarity in scientific communication, scientists need to develop a specific and unambiguous vocabulary, allowing them to efficiently define and communicate objects and concepts not available in the common language (Hirst, 2003). On the other hand, recent bibliometric analyses have stressed the fact that the (ab)use of scientific jargon, acronyms, and other technical terms has increased in recent years (Plavén-Sigray et al., 2017; Barnett and Doubleday, 2020). Such extensive use of jargon may hinder communication not only between scientists and the general public, but also among researchers from different backgrounds and disciplines (Martínez and Mammola, 2021). When reading an hypothetical text such as this one: "the long-term dynamics of hypolimnetic and epilimnetic DOC, POC, and TEP in the deep holo-oligomictic Lake Maggiore during its period of

Corresponding author: diego.fontaneto@cnr.it

Key words: Aquatic ecology, bibliometrics, citations, hydrobiology, jargon, lake ecology, oceanography.

Received: 10 June 2021.

Accepted: 27 July 2021.

This work is licensed under a Creative Commons Attribution NonCommercial 4.0 License (CC BY-NC 4.0).

${ }^{\circ}$ Copyright: the Author(s), 2021

Licensee PAGEPress, Italy

J. Limnol., 2021; 80(3):2042

DOI: 10.4081/jlimnol.2021.2042 maximum eutrophication", everybody not working on aquatic ecology may feel again like a child, "bathed in a rich, warm fluid of sounds" (quotation from Montgomery, 1989), without understanding their meaning. The evil of jargon abuse impacts communication at many levels, and it is perhaps more damaging when it involves partial understanding given that many jargon terms have been taken and adapted from everyday use English words, such as "community", "population", or "pressure" (Ryan, 1985; Zukswert et al., 2019).

Ecology is one of the research fields that may suffer from an overuse of discipline-specific jargon (Adams et al., 1997), given that it is a highly multidisciplinar endeavour often encompassing analyses across different environments, taxa, methods, and approaches. For example, in studies on evolution, the jargon used by evolutionary ecologists may be totally obscure to field ecologists; in spatially explicit field studies, the terms used for the geographic information systems may be unfamiliar for lab experimental ecologists; the jargonish description of statistical analyses may leave empiricists with no clue about the meaning of the procedures. Whereas it might be the case that the use of a specialized terminology in certain sections of a paper, such as the material and methods, might not be easy to avoid, the abuse of jargon is difficult to justify in other sections that are meant to attract the attention of the readers, like the abstract and the title (Mabe and Amin, 2002).

If we narrow the focus of ecology to aquatic ecology, the specialised field of research of our journal, a general ecologist may immediately notice that the Journal of Limnology has jargon even in its title. Even if the term 'limnology' exists in the Merriam-Webster English dictionary (https://www.merriam-webster.com/dictionary/limnology; retrieved on May 14, 2021) and it may seem familiar to freshwater ecologists and to readers knowledgeable in

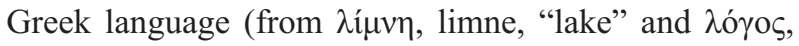
logos, "knowledge"), the vast majority of people, of scien- 
tists, and even of ecologists, may not know what such term means. The name of the journal, of course, has its roots in the long history of the science of limnology (Bertoni and Bertoni, 2021), which starts with the studies of Francois A. Forel in Lac Léman (Switzerland) (Forel, 1892-1904) and continues with a long tradition amongst European non-English speaking researchers (Vincent and Bertola, 2014; Bertoni, 2018) in a time in which English was not yet the universal language of science (Bertoni and Bertoni, 2021).

However, with the change of linguistic paradigms in research and the standard use of English as the language of science, the term limnology might be considered as a jargon, likely having negative effects on scientific visibility and communication (Orwell, 1946). Given this potentially negative effect, the aim of this study is to analyse whether the use of the term 'limnology' could have an effect on the way limnologists work, publish their research, and attract the interest of other scientists, in comparison to other fields of aquatic ecology. The analyses we performed were based on a literature search for the term 'limnology', for terms with a similar or partially overlapping meaning but which are easier to understand for a wider readership ('lake ecology' and 'hydrobiology'), and for the equivalent term used for marine aquatic studies, namely 'oceanography', as indeed limnology was originally considered as the "oceanography of lakes" (Forel, 1892-1904). From the literature search, we extracted relevant information to understand trends in the publishing activities within each of the four topics, and then compared them to identify whether limnologists work differently and/or have a different outreach than other aquatic ecologists. If this is the case, and the jargon 'limnology' has a detrimental effect, we have a set of a priori expectations affecting certain bibliometric traits, namely, number of papers, number of co-authors, length of the reference list, length of the paper, number of citation over time, and abstract's readability.

The number of papers published in limnology, if the term is indeed detrimental, should diminish through time, or at least, should have a lower rate of increase than other terms like lake ecology or oceanography, easier to be understood by a wider scientific and non-scientific audience. Other trends that could be visible refer to the number of coauthors in a paper: more co-authors, especially if having different backgrounds, would work more willingly together to publish papers with a broader outreach (Falkenberg and Tubb, 2017). Thus, we expect that limnological papers would have fewer authors than papers in similar fields, and that such difference would increase through time, given the current scientific trend of multi-authored publications (Elango and Rajendran, 2012; Castelvecchi, 2015; Kumaresan et al., 2016). The length of a paper could also differ between explicitly limnological papers and other papers on aquatic ecology, with differences through time, even if we do not have a clear expectation for such a trend.
Another difference that we expect is in the number of cited references in each paper: if the field is narrow and with a limited number of papers, the reference list could follow the same trends (Evans, 2008; Bornmann and Mutz, 2015; Fox et al., 2016). As a consequence of reduced visibility and reduced impact to a broader scientific audience for the use of jargon (Martínez and Mammola, 2021), we expect that the number of citations received by papers explicitly mentioning limnology could be lower than those of similar papers, and that such difference could increase through time. Conversely, the number citations in the reference list might also affect the impact of the publications (Mammola et al., 2021).

If papers mentioning limnology do not aim at reaching a broader audience, we expect that their readability would also suffer compared to other papers in aquatic ecology. We used the Flesch reading ease (Flesch, 1948) as an index to measure readability (Plavén-Sigray et al., 2017). Similar differences in writing style might also be reflected in the length of a paper, which could also differ between explicitly limnological papers and other papers on aquatic ecology, with differences through time. Being aware of whether such differences between limnology and other fields of aquatic ecology exist is pivotal for those limnologists willing to increase their visibility and gain a wider impact amongst other scientists, as well as towards the general public.

To conclude our bibliometric analysis of limnological papers, we analysed whether their scientific impact, approximated as the number of citations that a paper attracts after it is published, is comparable to similar research topics, and whether it can be affected by the way limnologists work and publish their papers.

Far from an attempt to impose any particular writing style to other limnologists, our aim with this analysis is to increase awareness of the uniqueness of limnology to its community of researchers with the hope that the results of our literature survey could bring insights on how to reach a broader audience. Ideally, this will contribute to further increasing the impact of the research performed within our field by making it more friendly and comprehensible for those scientists who do not share our limnological linguistic background, but would like to exploit lakes as models for addressing more general scientific questions (Hortal et al., 2014; Itescu, 2019).

\section{METHODS}

\section{Literature search}

On January $4^{\text {th }} 2021$, we performed a search for topic in the Clarivate Web of Science (WoS) using four keywords, namely 'limnolog*', 'lake ecolog*', 'hydrobiolog*', and 'oceanograph*' in order to find all publications dealing with the four topics published from 
1965 to 2020. In the WoS notation, the asterisks allows a user to retrieve all declinations of the searched term; for example limnolog* matches not only 'limnology' but also 'limnological'. For each of the papers found with the four search keyword, we extracted all available information in the WoS, including for example publication type (e.g., research article, review, editorial, etc.), list of authors, title, abstract, year of publication, number of cited references, number of pages, and number of citations. We stored the dataset in a text file, available as supplementary material at https://osf.io/s9mqh/.

\section{Data handling}

We managed the dataset with the $\mathrm{R}$ software version 4.0.3 (R Core Team, 2020), especially with packages 'bazar' version 1.0.11 (Poncet, 2019), 'dplyr' version 1.0.3 (Wickham et al., 2021), and 'tidyr' version 1.1.2 (Wickham, 2020) to extract summary information that would be relevant to address our hypotheses. We wrote our own functions to handle the data and check the correct formats, to remove papers from 2021, to restrict the analyses to journal articles only, to calculate the number of authors, and to calculate the Flesch reading ease for titles and abstracts.

The Flesch Reading Ease, FRE, from Flesch (1948), is an index of readability calculated based on the number of syllables per word and the number of words in each sentence, with this formula:

Flesch reading ease $=206.835-[1.015 *($ words/sentences) $-84.6 *$ (syllables/words)]

whereby a lower readability is indicated by a lower score. To correctly separate and count words and sentences, some preliminary work was necessary to clean the text by removing numbers, punctuation (except '.', '!', and '?'), dots within text, specific strings (e.g. 'et al.', 'sic!'), empty white spaces, etc. In addition, we used the R package 'quanteda' version 2.1.2 (Benoit et al., 2018) to count syllables.

\section{Statistical analyses}

The first question we asked was whether the number and annual distribution of published papers that we obtained with the keyword 'limnolog*' differed from those obtained with the other three search terms. To do so, we calculated the number of papers per year for each topic, together with other yearly summary statistics. Then, we performed a Generalised Additive Model (GAM) with the number of papers as a response variable, testing the effect of differences between topics (a factor with four levels), a smooth function of year of publication (a discrete variable from 1965 to 2020), and the interaction term between topic and year. We run the model with the $\mathrm{R}$ package 'gam' v1.20 (Hastie, 2020) assuming a Poisson distribu- tion of residuals for count data (Crawley, 2012) and a log link function to achieve positive fitted values. We checked model fit with the 'check_model' function of the R package 'performance' version 0.6.1 (Lüdecke et al., 2020). Following the results of GAM, we assessed statistical significance of the differences between pairs of levels for categorical variables with a post-hoc test using the $\mathrm{R}$ package 'emmeans' version 1.5.3 (Lenth, 2020).

After the check for the main temporal trend in number of papers, we addressed the other scientometric aspects, namely accounting for temporal trends and differences between topics in the number of authors for each paper, in the number of pages, in the number of cited references, in the number of citations, and in the readability of abstract and title. Each of the metrics summarising these aspects was used as a response variable in a GAM, following the same rationale described for the previous analysis. Once again a Poisson distribution was assumed for count data, whereas we used a Gaussian distribution for the Flesch reading ease as it may assume negative and non-integer values. For the Flesch reading ease, we removed extreme isolated values, potential outliers likely due to mistakes in the calculations, by visually inspecting the distribution of the values. For some analyses, the models were repeated excluding the older literature and focusing only on the papers published in the last thirty years.

In addition, we explored whether the impact that a single paper had on the scientific literature was affected by the other features we measured, namely differences between topics, number of authors, number of pages, number of citations, and abstract readability. Given that old papers had more time to accumulate citations than recent ones, we obtained a measurement of citations unaffected by age by performing a GAM with the number of citations as a function of age of the paper and then extracted the Pearson residuals from the model. The age-residual number of citations was used as the response variable in a generalized additive mixed model (GAMM). The model had four numerical metrics (number of authors, number of pages, number of references, and abstract readability) as explicit explanatory variables, in addition to their interaction with differences between topics. We accounted for differences between journals in attracting citations by including the identity of the journal as a random effect in the model. We performed the GAMM using the R package 'mgcv' version 1.8.33 (Wood, 2017). We then obtained a post-hoc comparison between topics with a Wald test using the R package 'itsadug' version 2.4 (van Rij et al., 2020).

Due to the large number of data and to the fact that we performed several analyses on the same data, we used a conservative approach in the identification of significance, and considered an alpha level for significance of 0.001 instead of the usually accepted 0.05 , without per- 
forming any formal adjustment (Crawley, 2012). We generated all graphical output with the R package ggplot2 version 3.3.3 (Wickham, 2016) with colours from the $R$ package RColorBrewer version 1.1.2 (Neuwirth, 2014).

The $\mathrm{R}$ codes used for the analyses and to obtain the graphics are available in GitHub: https://github.com/CNRIRSA-MEG/metaR/tree/master/lib/limnology.

\section{RESULTS}

The literature search provided a raw dataset with 55,449 literature records. After discarding the non-journal items and the papers published in 2021, we retained a total of 48,506 literature records for the analyses. Of these, 23,019 (47.5\%) belonged to lake ecology, 20,850 (43.0\%) to oceanography, 3,930 (8.1\%) to limnology, and 707 (1.5\%) to hydrobiology. The number of papers was significantly different between the four topics (Tab. 1), and the post-hoc test revealed that all pairwise comparisons between topics were significant (emmeans: all $p<0.0001)$. For all searched terms, we observed an increase in the number of papers over time, but the rate of increase was not the same: lake ecology and limnology had very similar number of papers in the '70es and ' $80 \mathrm{es}$, but from the beginning of the '90es the number of papers on lake ecology increased more rap- idly than for limnology, reaching and overcoming the number of papers on oceanography (Fig. 1).

Overall, our search captured papers published in 3,662 journals (Supplementary Tab. S1). The journal with the highest number of papers was Hydrobiologia, with 1,725 papers (Tab. 2), whereas the Journal of Limnology ranked $43^{\text {rd }}$, with 183 papers (Supplementary Tab. S1). Several journals published papers on both freshwater and marine habitats, e.g. Hydrobiologia, PLoS ONE, Science of the Total Environment (Tab. 2).

The number of authors per paper significantly increased through time, differently between the four topics (Fig. 2A, Tab. 3), but not between limnology and lake ecology (Supplementary Tab. S2).

The number of pages increased through time and with differences between topics (Fig.2B, Tab. 3, Supplementary Tab. S2). Yet, when restricting the analyses from 1990 onwards we found no significant differences due to temporal trends (GAM: $\mathrm{F}=2.8, \mathrm{p}=0.0917$ ), still confirming the differences between topics ( $\mathrm{F}=62.1, \mathrm{p}<0.0001)$.

The number of references also increased through time with differences between topics (Fig. 2C, Tab. 3, Supplementary Tab. S2). In this case, restricting the analyses from 1990 onwards the results remained significant as for the dataset from 1965, with the same quantitative differences and trend (results not shown).

Tab. 1. Results of the Generalised Additive Model to explain the number of papers as a function of differences between topics, of temporal trends [smooth function of year of publication, indicated with ' $\mathrm{s}(\mathrm{)}$ '], and of the differential effect of temporal trends among topics.

\begin{tabular}{lccccc} 
Predictor & Degrees of freedom & Sum of squares & Mean sum of squares & & F \\
topic & 3 & 24986.6 & 8328.9 & 1677.06 & P \\
\hline s(year) & 1 & 29487.6 & 29487.6 & 5937.49 & $<0.0001$ \\
\hline topic:s(year) & 3 & 2026.4 & 675.5 & 136.01 & $<0.0001$ \\
\hline Residuals & 208 & 1033.0 & 5.0 & & $<0.0001$ \\
\hline
\end{tabular}

Tab. 2. The ten journals with the highest number of papers, ordered by the total number of papers included in the dataset, with the number of papers recorded for each of the four topics. In addition, the Journal of Limnology, ranked $43^{\text {rd }}$, is also reported. For the full list of journals, see Supplementary Tab. S1.

\begin{tabular}{|c|c|c|c|c|c|}
\hline Journal & Hydrobiology & Lake ecology & Limnology & Oceanography & Total \\
\hline Hydrobiologia & 83 & 1159 & 395 & 88 & 1725 \\
\hline Journal of Geophysical Research - Oceans & 0 & 9 & 1 & 657 & 667 \\
\hline Marine Ecology Progress Series & 5 & 44 & 4 & 602 & 655 \\
\hline PLoS One & 1 & 315 & 15 & 254 & 585 \\
\hline Science of the Total Environment & 3 & 436 & 48 & 61 & 548 \\
\hline Deep-Sea Research Part II - Topical Studies in Oceanography & 1 & 0 & 7 & 510 & 518 \\
\hline Freshwater Biology & 8 & 398 & 96 & 1 & 503 \\
\hline Journal of Great Lakes Research & 0 & 425 & 66 & 2 & 493 \\
\hline Limnology and Oceanography & 1 & 180 & 109 & 150 & 440 \\
\hline Canadian Journal of Fisheries and Aquatic Sciences & 0 & 252 & 57 & 101 & 410 \\
\hline Journal of Limnology & 3 & 113 & 67 & 0 & 183 \\
\hline
\end{tabular}


The number of citations too increased through time (with an expected decrease in recent times, due to lack of time to accumulate citations) with significant differences between topics (Fig. 2D, Tab. 3, Supplementary Tab. S2).

Readability of abstracts (after removal of 40 outliers) diminished through time (Fig. 2E) whereas that of titles (after removal of 36 outliers) increased through time (Fig. 2F) (Tab. 3). In both cases, differences between the topics (Tab. 3) were due to only oceanography being different from some of the other topics (Supplementary Tab. S2). Also for readability, when restricting the analyses from 1990 onwards the results did not change in their quantitative differences between topics and in their temporal trends (results not shown).

The number of citations was different between the four topics (Tab. 4). Of the six possible pairwise comparisons between topics, only three differed significantly (Wald test: lake ecology $>$ limnology, $\mathrm{p}<0.0001$; lake ecology $>$ oceanography, $\mathrm{p}<0.0001$; oceanography $>$ limnology, $\mathrm{p}=0.003$ ). The effect of the differences in citations between topics interacted with the other predictors (Fig. 3, Tab. 4). The number of authors increased the number of citations for all topics, but after a threshold number of authors, the number of citations seems to decrease (Fig. 3A). The number of pages influenced the number of citations only for papers in oceanography (Tab. 4), with a hump-shaped relationship (Fig.3B). The

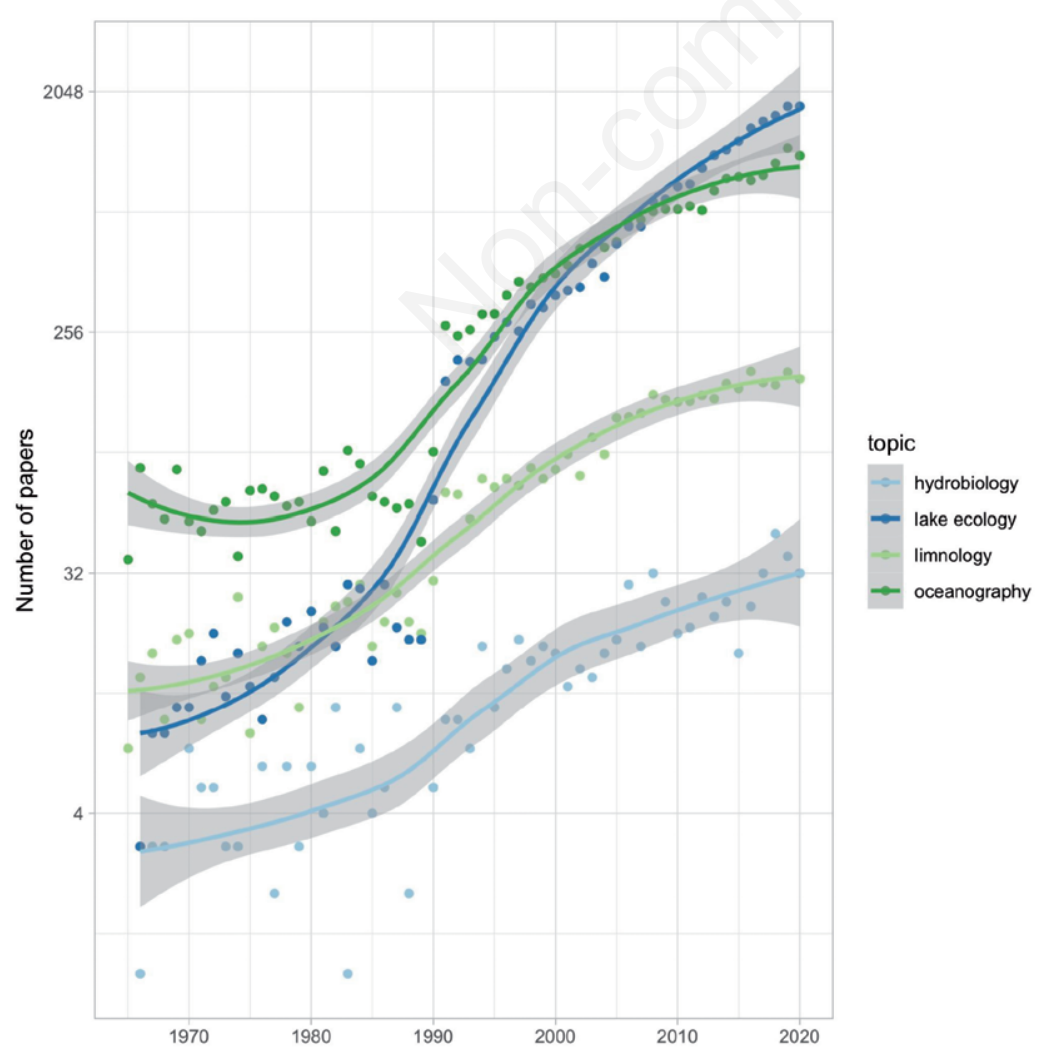

number of cited references significantly affected the number of citations (Tab. 4), with a positive effect for oceanography and a hump-shaped relationship for the three freshwater topics (Fig. 3C). Abstract readability had a significant effect only for limnology (Tab. 4), with a decreasing effect (Fig. 3D): apparently, papers with more readable abstracts gather fewer citations for limnology.

\section{DISCUSSION}

\section{Temporal trends between topics}

The number of papers increased through time for all the four topics, as expected due to the steady increase in the scientific publications (De Rond and Miller, 2005; Bornmann and Mutz, 2015). The slope of the increase for limnology was not very different from that of oceanography and hydrobiology (Fig. 1), but papers mentioning lake ecology disproportionately increased from 1990, starting at the same level as limnology but then reaching and overtaking oceanography since 2010 . Thus, the use of the term 'limnology' as a topic had a detrimental effect: its synonym 'lake ecology' had a significantly higher increase, leaving behind traditional limnologists using the term limnology in their papers in the number of published papers. Notably, and perhaps ironically, the term 'lake ecology' is used more fre-
Fig. 1. Number of published papers from 1965 to 2020 from a Web of Science search for topic with keywords 'limnolog*' in comparison to 'hydrobiolog*', lake ecolog*', and 'oceanograph*'. The year of publication is on the $\mathrm{x}$ axis and the number of papers on the $\mathrm{y}$ axis on a log scale; the four topics are identified by four different colours for the points and for the trend lines with $95 \%$ confidence intervals as grey shaded areas. 
quently than 'limnology' even by the authors publishing in the Journal of Limnology (Tab. 2).

Among the four topics we analysed, the term hydrobiology was found in very few papers: thus, we will not discuss the results obtained in the comparisons with this topic, given that low sample size may affect the results.

All topics had a similar temporal trend in the increase in the number of authors and in the number of cited references, in line with a common pattern in the scientific literature (Regalado, 1995; Elango and Rajendran, 2012; Fox et al., 2016; Kumaresan et al., 2016). The increasing trend in the length of each paper, measured as the number of pages, reached a plateau in the 90 s and then the length of the papers did not change for the three main topics.

Readability decreased in the abstract, but apparently increased in the titles, for all topics in aquatic sciences. Such a trend is in line with the general changes in the scientific literature, with text that is getting harder to understand for a broader readership (Ball, 2017; PlavénSigray et al., 2017) but titles that try to be shorter and catchier to attract attention (Deng, 2015; Letchford et al., 2015).

\section{Scientific impact for limnologists}

The average number of citations was lower for papers citing limnology than for those citing oceanography or lake ecology, especially from the 80es (Figure 2D). Not without critics (Nieminen et al., 2006; Todd and Ladle, 2008; Aksnes et al., 2019), the number of citations repre-

Tab. 3. Results of the Generalised Additive Model to explain the number of authors, number of pages, number of references, number of citations, readability of abstract, and readability of title, as a function of differences between topics (See Tab. 3 for post-hoc tests on the pairwise differences between topics), of temporal trends [smooth function of year of publication, indicated with ' $\mathrm{s}(\mathrm{)}$ '], and of the differential effect of temporal trends among topics.

\begin{tabular}{|c|c|c|c|c|c|}
\hline Number of authors & Degrees of freedom & Sum of squares & Mean sum of squares & $\mathbf{F}$ & $\mathbf{P}$ \\
\hline topic & 3 & 369 & 123.0 & 41.3 & $<0.0001$ \\
\hline $\mathrm{s}($ year) & 1 & 13437 & 13436.7 & 4506.2 & $<0.0001$ \\
\hline topic:s(year) & 3 & 62 & 20.6 & 6.9 & 0.0001 \\
\hline Residuals & 48493 & 144599 & 3.0 & & \\
\hline Number of pages & Degrees of freedom & Sum of squares & Mean sum of squares & F & $\mathbf{P}$ \\
\hline topic & 3 & 657 & 218.8 & 42.6 & $<0.0001$ \\
\hline $\mathrm{s}($ year) & 1 & 593 & 593.2 & 115.6 & $<0.0001$ \\
\hline topic:s(year) & 3 & 414 & 137.9 & 26.9 & $<0.0001$ \\
\hline Residuals & 47901 & 245944 & 5.1 & & \\
\hline Number of references & Degrees of freedom & Sum of squares & Mean sum of squares & $\mathrm{F}$ & $\mathbf{P}$ \\
\hline topic & 3 & 14819 & 4940 & 152.2 & $<0.0001$ \\
\hline $\mathrm{s}($ year) & 1 & 98326 & 98326 & 3029.3 & $<0.0001$ \\
\hline topic:s(year) & 3 & 6736 & 2245 & 69.2 & $<0.0001$ \\
\hline Residuals & 48493 & 1573975 & 32 & & \\
\hline Number of citations & Degrees of freedom & Sum of squares & Mean sum of squares & $\mathbf{F}$ & $\mathbf{P}$ \\
\hline topic & 3 & 9530 & 3177 & 30.5 & $<0.0001$ \\
\hline $\mathrm{s}($ year $)$ & 1 & 144906 & 144906 & 1392.6 & $<0.0001$ \\
\hline topic:s(year) & 3 & 3194 & 1065 & 10.2 & $<0.0001$ \\
\hline Residuals & 48495 & 5046241 & 104 & & \\
\hline Abstract readability & Degrees of freedom & Sum of squares & Mean sum of squares & $\mathrm{F}$ & $\mathbf{P}$ \\
\hline topic & 3 & 25328 & 8443 & 36.0 & $<0.0001$ \\
\hline $\mathrm{s}$ (year) & 1 & 111204 & 111204 & 474.3 & $<0.0001$ \\
\hline topic:s(year) & 3 & 2075 & 692 & 2.9 & 0.0314 \\
\hline Residuals & 44843 & 10513623 & 234 & & \\
\hline Title readability & Degrees of freedom & Sum of squares & Mean sum of squares & $\mathbf{F}$ & $\mathbf{P}$ \\
\hline topic & 3 & 12452 & 4151 & 4.0 & 0.0071 \\
\hline $\mathrm{s}($ year) & 1 & 1010083 & 1010083 & 980.8 & $<0.0001$ \\
\hline topic:s(year) & 3 & 132939 & 44313 & 43.0 & $<0.0001$ \\
\hline Residuals & 48493 & 49943284 & 1030 & & \\
\hline
\end{tabular}


sents the most used metric to assess the impact of a paper in the scientific literature (Jaffe and Trajtenberg, 2002; Abramo et al., 2010). Thus, every researcher would like to maximise the number of citations of its papers. For lim- nologists, apparently, one way to maximise citations would be not to use the term limnology but other synonyms that are easier to understand for a broader readership. In addition to the effect of the use of the term
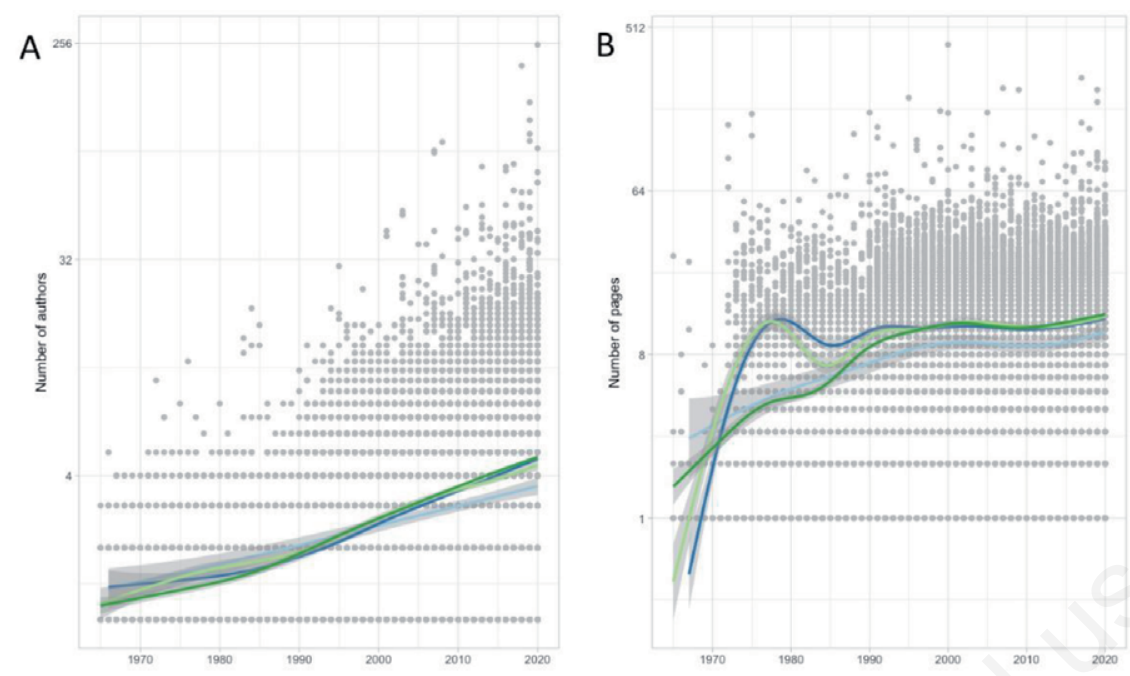

C

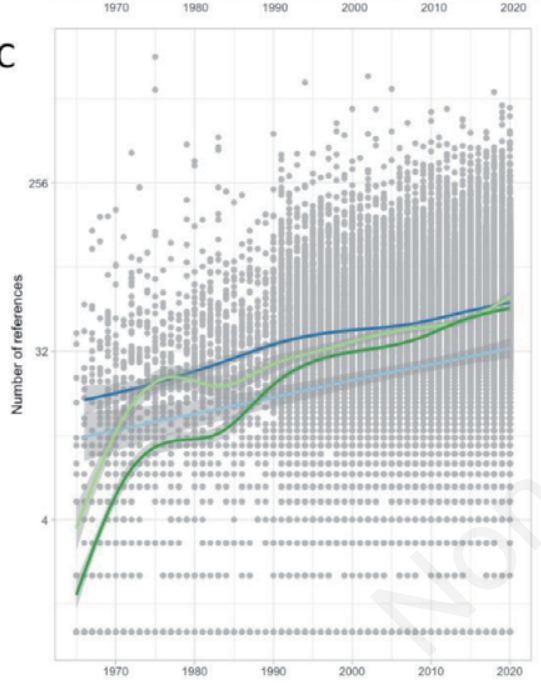

E

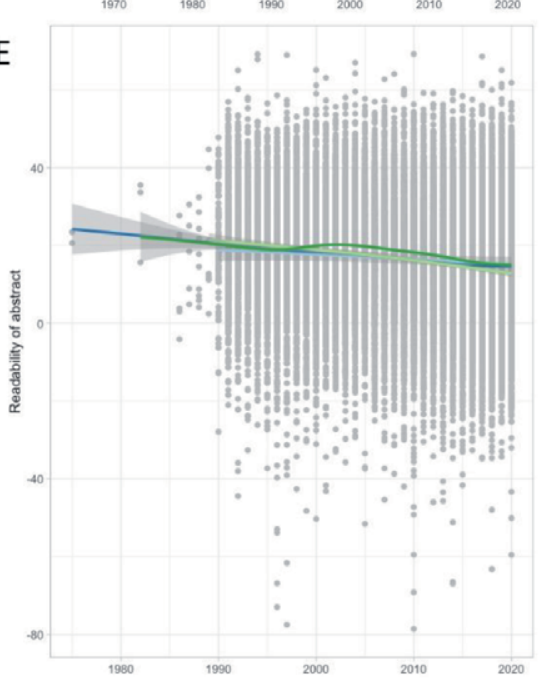

D

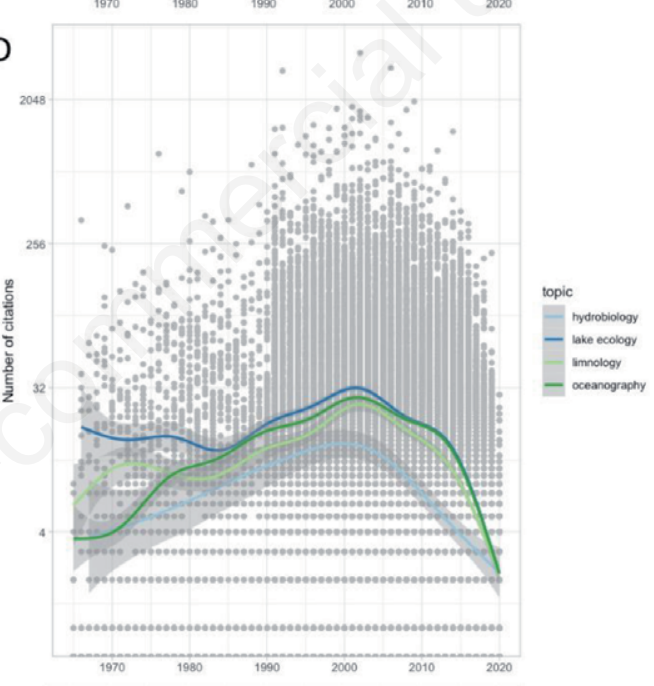

$\mathrm{F}$
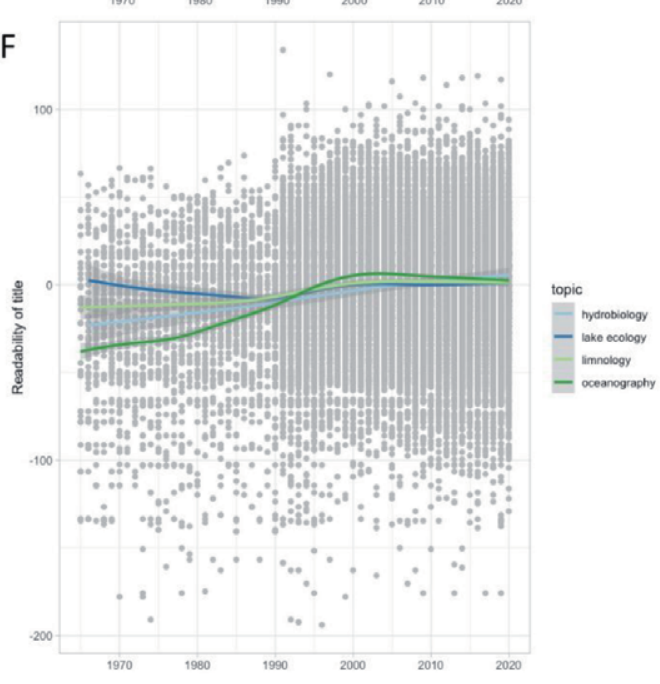

Fig. 2. Trends in different aspects of the differences in published papers from 1965 to 2020 from a Web of Science search by topic with keyword 'limnolog*' in comparison to 'hydrobiolog*', lake ecolog*', and 'oceanograph*'. The scientometric aspects refer to A) number of authors for each paper, B) number of pages, C) number of references, D) number of citations, E) readability of the abstract, and F) readability of the title. The year of publication is on the $\mathrm{x}$ axis, the aspects represented by count data (A to D) are reported on the y axis on a log scale, the aspects of readability report the actual values of the metric on the y axis; the four topics are identified by four different colours for the trend line with $95 \%$ confidence intervals as grey shaded areas. 
limnology, other features of a paper are known to potentially affect the number of citations in the ecological literature (Tahamtan et al., 2016).

A known trend in the number of citations is related to the number of co-authors: papers with more authors tend to attract more citations (Leimu and Koricheva, 2005a, b). The reasons for the effect are multiple, but the trend exists (Zeng et al., 2017). We found such an increasing trend for all four analysed topics, but only up to a threshold of about 30 to 100 authors (Fig. 3A). Limnology stood out as different from the other two major topics by the fact that the highest number of co-authors was 62, whereas it was well above 200 for lake ecology and for oceanography (Fig. 3A). Apparently, limnologists are not used to gathering a large number of co-authors for their papers, at least not as much as in the other fields of aquatic sciences.

The length of a paper may also influence the number of citations it attracts (Leimu and Koricheva, 2005b): our results support such a trend, but with a threshold effect around 50 pages, with longer papers not attracting any additional citations (Fig. 3B). This is generally explained by the fact that longer papers address a broader diversity of ideas and topics, thereby containing more citable information (Fox et al., 2016).

Also the number of cited references in a paper seems to correlate with the number of citations in the ecological literature (Ahlgren et al., 2018; Mammola et al., 2021): we found the same positive correlation in oceanography, whereas for limnology and lake ecology there seems to be a hump-shaped relationship with the number of citations steadily decreasing in papers with more than about 250 citations (Fig. 3C). Thus, increasing the number of cited references seems to work to attract citations to limnological studies, but only up to a certain level.

Finally, the readability of a paper may affect its impact in the number of citations a paper receives in the scientific literature (Lei and Yan, 2016; McCannon, 2019). Such a trend was visible, but again with a hump-shaped relationship: abstracts that were very easy to read had a decreasing number of citations for three major topics, potentially because their content was also too easy and maybe not novel (Yitzhaki, 2002; Habibzadeh and Yadollahie, 2010).

\section{CONCLUSIONS}

Papers that used the jargonish term 'limnology' had a limited impact in the scientific literature: the use of a term like 'lake ecology', which has a similar meaning but is easier to understand, correlates with more papers and more citations. Likewise, the use of a term like 'oceanography', which is the marine equivalent of 'limnology' but can be understood by most English-speaking reader (the greek root

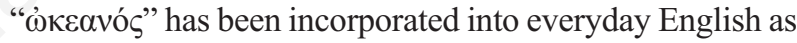
"ocean"), correlates with more papers and more citations. Unfortunately for limnologists and for the Journal of Limnology, the term we care about and that could allow us to

Tab. 4. Results of the Generalised Additive Mixed Model to explain the number of citations as a function of differences between topics, interacting with the [smooth function of, indicated with ' $\mathrm{s}(\mathrm{)}$ '] the number of authors, the number of pages, the number of references, and abstract readability (FRE, Flesch Reading Ease), with journal identity as a random effect. The acronym 'edf' stands for estimated degrees of freedom in the model.

\begin{tabular}{|c|c|c|c|}
\hline & edf & $\mathbf{F}$ & $\mathbf{P}$ \\
\hline topic & 3 & 29.72 & $<0.0001$ \\
\hline s(authors):hydrobiolog & 1.0 & 9.562 & 0.00199 \\
\hline s(authors):lake_ecolog & 3.7 & 97.636 & $<0.0001$ \\
\hline s(authors):limnolog & 1.0 & 60.811 & $<0.0001$ \\
\hline s(authors):oceanograph & 5.1 & 87.676 & $<0.0001$ \\
\hline s(pages):hydrobiolog & 1.0 & 8.858 & 0.00292 \\
\hline s(pages):lake_ecolog & 1.0 & 8.199 & 0.00419 \\
\hline s(pages):limnolog & 1.0 & 0.002 & 0.96243 \\
\hline s(pages):oceanograph & 2.8 & 37.316 & $<0.0001$ \\
\hline s(references):hydrobiolog & 2.7 & 27.878 & $<0.0001$ \\
\hline s(references):lake_ecolog & 8.2 & 207.233 & $<0.0001$ \\
\hline $\mathrm{s}($ references):limnolog & 4.2 & 97.935 & $<0.0001$ \\
\hline s(references):oceanograph & 8.2 & 191.229 & $<0.0001$ \\
\hline s(FRE abstract):hydrobiolog & 1.0 & 0.980 & 0.32221 \\
\hline s(FRE abstract):lake_ecolog & 1.0 & 0.006 & 0.93955 \\
\hline $\mathrm{s}(\mathrm{FRE}$ abstract):limnolog & 1.0 & 17.386 & $<0.0001$ \\
\hline s(FRE abstract):oceanograph & 1.0 & 8.010 & 0.00465 \\
\hline
\end{tabular}


reach the goal of understanding the functioning of freshwater systems limits our reach in the scientific literature. This raises a thorny question: is it time to rethink the name of the Journal of Limnology? We may not want to do so, as the journal still aims to serve the researchers who identify themselves as limnologists, regardless of the current fashion and trendiness of the term 'limnology'. One of the reviewers of this manuscript offered an insightful alternative explanation for the negative effect of the term limnology in comparison, for example, to the term 'ecology', which is nowadays one of the most popular branch of biology (in spite of the overuse of specific jargon; e.g., Anderson et al., 2021). The reviewer suggested that the term ecology is an inclusive one because it succeeded in grouping all the people involved in the scientific study of nature and in its conservation; conversely, the term limnology is a divisive one, which excludes river ecology, and to a certain extent also pond ecology, being traditionally mainly focused on large and deep lakes. Such cultural fragmentation has likely put limnology in a corner and probably this is the reason for the low success of the term. Tackling general scientific questions and being inclusive in our research, focusing on lakes as models to understand general problems in nature rather than as unique entities, with unique properties, hosting somehow exceptional processes, could increase visibility of limnology. That could be the reason why another journal with limnology in its title, Limnology and Oceanography, does not seem to suffer in terms of citations, providing hopes for future generations of limnologists. Let multidisciplinary research continue to bloom in our lakes!

\section{DATA ACCESSIBILITY}

The dataset with the raw literature data obtained from Web of Science is available as supplementary material at https://osf.io/s9mqh/. The R codes used for the analyses and to obtain the graphical output are available at GitHub: https:/github.com/CNR-IRSA-MEG/metaR/tree/master/ lib/limnology
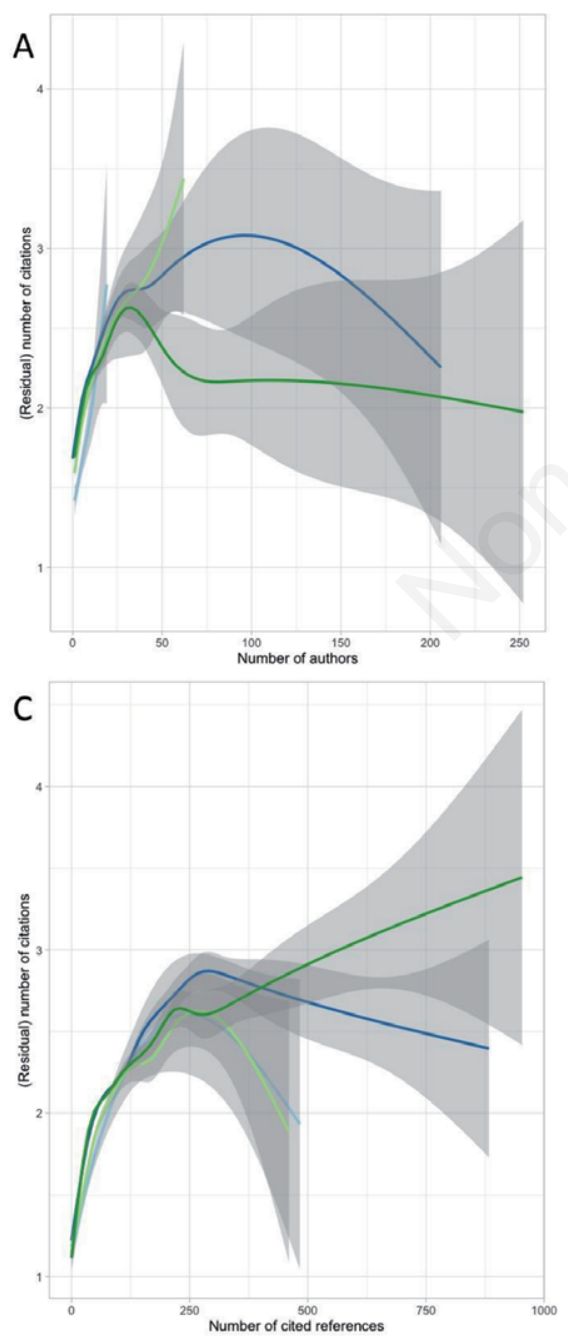

B
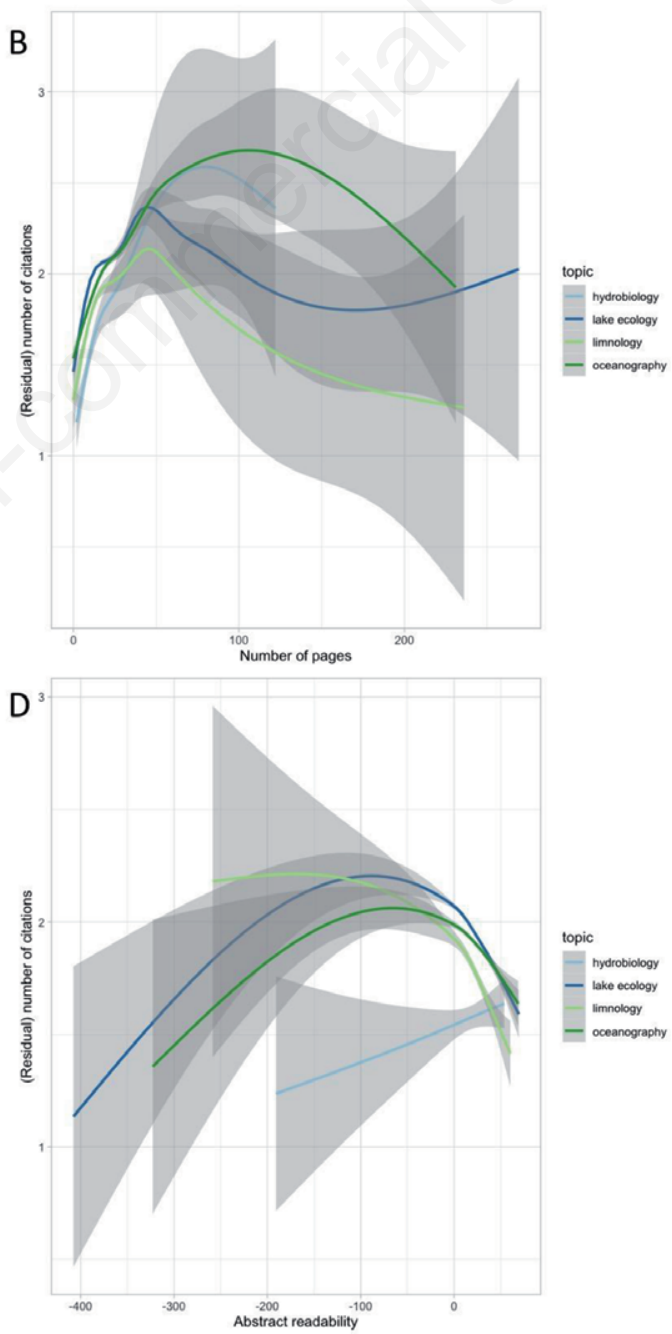

Fig. 3. Differential effects of (A) the number of authors, (B) the number of pages, $(C)$ the number of cited references, and (D) abstract readability on the age-residual number of citations, separately for the topic ' $l i m n o l o g$ *' in comparison to 'hydrobiolog*', 'lake ecolog*', and 'oceanograph*'. The four topics are identified by four different colours for the trend line, using the same colour codes of Figures 1 and 2, with $95 \%$ confidence intervals marked as grey shaded areas. 


\section{SUPPLEMENTARY MATERIALS}

Dataset: The file db_all.txt contains the raw data from the literature search performed in Web of Science. It represents the starting dataset for the analyses.

Supplementary Tab. S1. List of 3662 journals ordered by the total number of papers included in the dataset, with the number of papers recorded for each of the four topics.

Supplementary Tab. S2. Significance of the pairwise comparisons between topics, obtained with emmeans post-hoc tests from the models of Tab. 2.

\section{REFERENCES}

Abramo G, D'Angelo C, Di Costa F, 2010. Citations versus journal impact factor as proxy of quality: could the latter ever be preferable? Scientometrics 84:821-833.

Adams DC, Bitetti MSD, Janson CH, Slobodkin LB, Valenzuela N, 1997. An 'Audience effect' for ecological terminology: use and misuse of Jargon. Oikos 80:632-636.

Ahlgren P, Colliander C, Sjögårde P, 2018. Exploring the relation between referencing practices and citation impact: a large-scale study based on Web of Science data. J. Ass. Inf. Sci. Tech. 69:728-743.

Aksnes DW, Langfeldt L, Wouters P, 2019. Citations, citation indicators, and research quality: an overview of basic concepts and theories. SAGE Open, 9(1), 2158244019829575.

Anderson SC, Elsen PR, Hughes BB, Tonietto RK, Bletz MC, Gill DA, Holgerson MA, Kuebbing SE, McDonough MacKenzie C, Meek MH, Veríssimo D, 2021. Trends in ecology and conservation over eight decades. Frontiers in Ecology and the Environment 19:274-282.

Ball P, 2017. It's not just you: science papers are getting harder to read. Nature News.

Barnett A, Doubleday Z, 2020. Meta-research: The growth of acronyms in the scientific literature. Elife 9:e60080.

Benoit K, Watanabe K, Wang H, Nulty P, Obeng A, Müller S, Matsuo A, 2018. quanteda: An R package for the quantitative analysis of textual data. J. Open Source Soft. 3:774.

Bertoni R., 2018. Laghi e scienza: introduzione alla limnologia. eBook, 256 pp. Downloaded at http://www.aiol.info/wpcontent/uploads/Laghi-e-Scienza-100618.pdf

Bertoni R, Bertoni F, 2021. Preserving the heritage of limnology in Italy. J. Limnol.: this issue.

Bornmann L, Mutz R, 2015. Growth rates of modern science: A bibliometric analysis based on the number of publications and cited references. J. Ass. Inf. Sci. Tech. 66:2215-2222.

Bullock OM, Colón Amill D, Shulman HC, Dixon GN, 2019. Jargon as a barrier to effective science communication: Evidence from metacognition. Publ. Underst. Sci. 28:845-853.

Castelvecchi D, 2015. Physics paper sets record with more than 5,000 authors. Nature News, https://doi.org/10.1038/nature. 2015.17567

Crawley MJ, 2012. The R Book. Wiley, Chichester, UK.

De Rond M, Miller AN, 2005. Publish or perish: bane or boon of academic life?. J. Manag. Inq. 14:321-329.

Deng B, 2015. Papers with shorter titles get more citations. Nature News.
Elango B, Rajendran P, 2012. Authorship trends and collaboration pattern in the marine sciences literature: a scientometric study. Int. J. Inform. Dissem. Tech. 2:166.

Evans JA, 2008. Electronic publication and the narrowing of science and scholarship. Science 321:395.

Falkenberg LJ, Tubb A, 2017. Undisciplined thinking facilitates accessible writing: A response to Doubleday and Connell. Trends Ecol. Evol. 32:894-895.

Flesch R, 1948. A new readability yardstick. J. Appl. Psychol. 32:221-233.

Forel FA, 1892-1904. Le Léman: monographie limnologique. F. Rouge, Lausanne.

Fox CW, Paine CT, Sauterey B, 2016. Citations increase with manuscript length, author number, and references cited in ecology journals. Ecol. Evol. 6:7717-7726.

Habibzadeh F, Yadollahie M, 2010. Are shorter article titles more attractive for citations? Crosssectional study of 22 scientific journals. Croatian Med. J. 51:165-170.

Hastie T, 2020. gam: Generalized Additive Models. R package version 1.20. https://CRAN.R-project.org/package=gam

Hortal J, Nabout JC, Calatayud J, Carneiro FM, Padial A, Santos AMC, Siqueira T, Bokma F, Bini LM, Ventura M, 2014. Perspectives on the use of lakes and ponds as model systems for macroecological research. J. Limnol. 73(s1):46-60.

Hirst R, 2003. Scientific jargon, good and bad. J. Tech. Wri. Commun. 33:201-229.

Itescu Y, 2019. Are island-like systems biologically similar to islands? A review of the evidence. Ecography 42:1298-1314.

Jaffe AB, Trajtenberg M, 2002. Patents, citations, and innovations: A window on the knowledge economy. MIT press.

Kumaresan R, Vinitha K, Kannan K, 2016. Journal of Aquatic Ecology (2005-2014): A Bibliometric Study. IALA-Journal 4:12-20.

Lei L, Yan S, 2016. Readability and citations in information science: evidence from abstracts and articles of four journals (2003-2012). Scientometrics 108:1155-1169.

Leimu R, Koricheva J, 2005a. Does scientific collaboration increase the impact of ecological articles?. BioScience 55:438-443.

Leimu R, Koricheva J, 2005b. What determines the citation frequency of ecological papers?. Trends Ecol. Evol. 20:28-32.

Lenth RV, 2020. emmeans: estimated marginal means, aka leastsquares means. R package version 1.5.3. https://CRAN.Rproject.org/package $=$ emmeans

Letchford A, Moat HS, Preis T, 2015. The advantage of short paper titles. Royal Society Open Science 2:150266.

Lüdecke D, Makowski D, Waggoner P, Patil I, 2020. Assessment of regression models performance. CRAN. Available from https://easystats.github.io/performance/

Mabe MA, Amin M, 2002. Dr Jekyll and Dr Hyde: author-reader asymmetries in scholarly publishing. In Aslib Proceedings 54:149-157.

Mammola S, Fontaneto D, Martínez A, Chichorro F, 2021. Impact of the reference list features on the number of citations. Scientometrics 126:785-799.

Martínez A, Mammola S, 2021. Specialized terminology reduces the number of citations of scientific papers. Proc. R. Soc. B. 288:20202581.

McCannon BC, 2019. Readability and research impact. Econom. Lett. 180:76-79. 
Montgomery SL, 1989. The cult of jargon: reflections on language in science. Sci. Cult. 1:42-77.

Nation I, 2006. How large a vocabulary is needed for reading and listening? Canad. Mod. Lang. Rev. 63:59-82.

Neuwirth E, 2014. RColorBrewer: ColorBrewer palettes. R package version 1.1-2. https://CRAN.R-project.org/package $=$ RColorBrewer

Nieminen P, Carpenter J, Rucker G, Schumacher M, 2006. The relationship between quality of research and citation frequency. BMC Med. Res. Meth. 6:42.

Orwell G, 1946. Politics and the English language. Horizon 13:252-265.

Plavén-Sigray P, Matheson GJ, Schiffler BC, Thompson WH, 2017. The readability of scientific texts is decreasing over time. Elife 6:e27725.

Poncet P, 2019. bazar: miscellaneous basic functions. R package version 1.0.11. https://CRAN.R-project.org/package=bazar

$\mathrm{R}$ Core Team, 2020. R: A language and environment for statistical computing. R Foundation for Statistical Computing, Vienna, Austria. URL https://www.R-project.org/.

Regalado A, 1995. Multiauthor papers on the rise. Science 268:25-26.

Ryan JN, 1985. The secret language of science or, radicals in the classroom. Am. Biol. Teach. 47:91-91.

Tahamtan I, Afshar AS, Ahamdzadeh K, 2016. Factors affecting number of citations: a comprehensive review of the literature. Scientometrics 107:1195-1225.
Todd P, Ladle R, 2008. Citations: poor practices by authors reduce their value. Nature 451:244.

van Rij J, Wieling M, Baayen R, van Rijn H, 2020. itsadug: Interpreting Time Series and Autocorrelated Data Using GAMMs. R package version 2.4.

Vincent WF, Bertola C, 2014. Lake physics to ecosystem services: Forel and the origins of limnology. Limnol. Oceanogr. e-Lect. 4:1-47.

Wickham H, 2016. ggplot2: elegant graphics for data analysis. Springer-Verlag New York.

Wickham H, 2020. tidyr: tidy messy data. R package version 1.1.2. https://CRAN.R-project.org/package=tidyr

Wickham H, François R, Henry L, Müller K, 2021. dplyr: A grammar of data manipulation. $\mathrm{R}$ package version 1.0.3. https://CRAN.R-project.org/package $=$ dplyr

Wood SN, 2017. Generalized Additive Models: An Introduction with R (2nd edition). Chapman and Hall/CRC.

Yitzhaki M, 2002. Relation of the title length of a journal article to the length of the article. Scientometrics 54:435-447.

Zeng A, Shen Z, Zhou J, Wu J, Fan Y, Wang Y, Stanley HE, 2017. The science of science: From the perspective of complex systems. Phys. Rep. 714:1-73.

Zukswert JM, Barker MK, McDonnell L, 2019. Identifying troublesome jargon in biology: Discrepancies between student performance and perceived understanding. CBE-Life Sci. Ed. 18:ar6. 